\title{
ACLARACIONES AL TRABAJO DE TAUBER (1999) LOS VERTEBRADOS DE LA FORMACIÓN SANTA CRUZ (MIOCENO INFERIOR-MEDIO) EN EL EXTREMO SURESTE DE LA PATAGONIA Y SU SIGNIFICADO PALEOECOLÓGICO
}

\author{
Sergio F. VIZCAÍNO \\ Univ. Nacional de La Plata, Fac. de Ciencias Naturales y Museo de la Plata, \\ Depto. Científico Paleontología de Vertebrados, Paseo del Bosque s/n, $1900 \mathrm{La}$ \\ Plata, Argentina
}

En el trabajo del Dr. Adán Tauber, intitulado "Los vertebrados de la Formación Santa Cruz (Mioceno InferiorMedio) en el extremo sureste de la Patagonia y su significado paleoecológico", y publicado en el n 14 (2): 173-182 de la Revista Española de Paleontología, se han hecho algunas referencias erróneas a trabajos de mi autoría.

En el primer párrafo de la página 176 dice textualmente: "Los Stegotheriini y otros Xenarthra fueron empleados como indicadores de condiciones cálidas y húmedas, debido a que su último registro corresponde a la 'Edad Santacrucense' (Scillato Yané, 1986). La ausencia de este grupo de Cingulata en depósitos de 'Edad Friasense' fue considerada como evidencia de condiciones más xéricas y frías que las de la 'Edad Santacrucense' (Vizcaíno, 1994a), originándose un pensamiento circular. Además, se registraron con posterioridad dos Stegotheriini en las formaciones Río Frías y Collón Curá (Pardiñas, 1991; Vizcaíno, 1994b) ambas de 'Edad Friasense', por lo que esta hipótesis climatológica debe ser replanteada, sobre todo si los fundamentos para reconocer estas dos 'edades' han sido cuestionados (Tauber, 1997a). Independientemente de la discusión y de las conclusiones de este trabajo, la abundancia de rellenos de grietas de desecación y costras calcáreas en el nivel fosilífero 10 (Tauber, 1994), de donde procede Stegotherium tessellatum Ameghino, indica que, al menos esta especie, habría tolerado condiciones de un clima con variaciones estacionales bien marcadas."

Es conveniente hacer las siguientes aclaraciones:

En el trabajo citado como Vizcaíno 1994a, publicado en el tercer número del volumen 31 de Ameghiniana, dice en el segundo párrafo de la página 289: "La presencia de formas mirmecófagas extremas como los Stegotheriini y Vermilingua durante la Edad Santacrucense (Scillato-Yané, 1986; Carlini et al., 1992) es indicativa de un clima cálido, sea seco o húmedo, al que correspondería una vegetación de tipo chaqueña o selvática, respectivamente o quizás alternativamente en el decurso temporal. La evidencia aportada por la presencia de otros Xenarthra como ciertos Tardigrada relacionados con los 'perezosos' arbóreos vivientes (Scillato-Yané, 1986) y de otros mamíferos indicadores permite postular que el clima era cálido y húmedo y la vegetación, probablemente, una sabana arbolada."

En el párrafo siguiente dice: “... A partir del Mioceno medio (Edad Mamífero Friasense), período del que sólo se conoce una placa de Stegotheriini indet. (Vizcaíno, 1990; Pardiñas, 1991), comienza un proceso de atemperación y aridización que se correlaciona con la elevación de la cordillera andina (Pascual, 1984a y 1984b)."

Entiendo que queda claro que, por un lado, nunca señalé que los Stegotheriini indican por sí solos que durante el Santacrucense hayan predominado condiciones húmedas. Por otro, que, independientemente de que el conocimiento actual ha cambiado la concepción de lo que en su momento se llamaba Edad Mamífero Friasense, en mi trabajo no se atribuyen condiciones xéricas y frías al Friasense sobre la base de la ausencia de Stegotheriini, sino por el cuerpo de conocimientos preexistentes resumidos en la bibliografía citada.

También resulta claramente errónea la aseveración de que "... se registraron con posterioridad dos Stegotheriini en las formaciones Río Frías y Collón Curá (Pardiñas, 1991; Vizcaíno, 1994b)...". En el mismo trabajo citado como Vizcaíno 1994a se menciona la presencia de Stegotheriini en el Friasense y se proporciona la fuente. Además, el trabajo citado como Vizcaíno 1994b fue publicado en el primer número del mismo volumen 31 de Ameghiniana, es decir, que es anterior y no posterior al trabajo citado previamente.

Todo lo señalado no desacredita lo expresado por el Dr. Tauber en el sentido de que Stegotherium variegatum habría tolerado variaciones estacionales, cuestión en la que me encuentro completamente de acuerdo y que puede deducirse de lo expresado en mi trabajo de Ameghiniana $31(3)$. 